\title{
Effector granules in human T lymphocytes: the luminal proteome of secretory lysosomes from human T cells
}

\author{
Hendrik Schmidt ${ }^{1}$, Christoph Gelhaus ${ }^{2}$, Melanie Nebendahl', Marcus Lettau', Ralph Lucius ${ }^{3}$, Matthias Leippe $^{2}$,
} Dietrich Kabelitz', Ottmar Janssen ${ }^{1 *}$

\begin{abstract}
Background: Cytotoxic cells of the immune system have evolved a lysosomal compartment to store and mobilize effector molecules. In T lymphocytes and NK cells, the death factor FasL is one of the characteristic marker proteins of these so-called secretory lysosomes, which combine properties of conventional lysosomes and exocytotic vesicles. Although these vesicles are crucial for immune effector function, their protein content in $T$ cells has so far not been investigated in detail.

Results: In the present study, intact membranous vesicles were enriched from homogenates of polyclonally activated T cells and initially characterized by Western blotting and electron microscopic inspection. The vesicular fraction that contained the marker proteins of secretory lysosomes was subsequently analyzed by 2D electrophoresis and mass spectrometry. The proteome analysis and data evaluation revealed that $70 \%$ of the 397 annotated proteins had been associated with different lysosome-related organelles in previous proteome studies.

Conclusion: We provide the first comprehensive proteome map of T cell-derived secretory lysosomes with only minor contaminations by cytosolic, nuclear or other proteins. This information will be useful to more precisely address the activation-dependent maturation and the specific distribution of effector organelles and proteins in individual T or NK cell populations in future studies.
\end{abstract}

\section{Background}

Cytotoxic T lymphocytes (CTL) and Natural Killer (NK) cells are the main cytotoxic effector cells of the immune system. In order to effectively eliminate virus-infected and tumorigenic cells, they rapidly mobilize effector molecules including granzymes, perforin, granulysin and the death factor FasL (CD178) that are presumably stored in preformed organelles termed secretory lysosomes (SL) [1]. Secretory lysosomes combine degradative properties of conventional lysosomes with characteristics of exocytotic vesicles. At the level of morphology, conventional and secretory lysosomes are hardly distinguishable and both appear to represent endpoints of an endocytotic pathway and are formed by fusion and fission of endosomes and lysosomes [2].

\footnotetext{
* Correspondence: ojanssen@email.uni-kiel.de

'Institute of Immunology, Christian-Albrechts-University, UK S-H Campus Kiel, Kiel, Germany

Full list of author information is available at the end of the article
}

Similar to conventional lysosomes, large membrane areas are covered by lysosome-associated membrane-proteins (LAMPs) including LAMP-1 (CD107a), LAMP-2 (CD107b) and LAMP-3 (CD63) [3-5]. However, secretory effector lysosomes are characterized by a specific set of membrane and luminal marker proteins [6,7]. The current consensus is that SL of CTLs and NK cells carry the aforementioned effector proteins either in the lysosomal lumen (granzymes, perforin and granulysin) or as characteristic transmembrane compounds (FasL) [8-10].

Recently, we provided a protocol that allows a substantial enrichment of intact SL from in vitro expanded lymphocyte populations [11]. Employing this procedure for subcellular fractionation of a crude organelle preparation, we obtained a fraction of intact vesicles that is significantly enriched in SL marker proteins. We were thus able to report the first comprehensive analysis of the luminal proteome of secretory lysosomes from NK cells [12]. At that time, 234 different proteins were
C Biomed Central

() 2011 Schmidt et al; licensee BioMed Central Ltd. This is an Open Access article distributed under the terms of the Creative Commons Attribution License (http://creativecommons.org/licenses/by/2.0), which permits unrestricted use, distribution, and reproduction in any medium, provided the original work is properly cited. 
identified by mass spectrometry, $77 \%$ of which had been associated with SL or other lysosomal compartments before. Applying 2D difference gel electrophoresis, we also described a cell line-specific distribution of functionally relevant proteins in SL from human NK cell lines and primary NK cells [12].

Based on this study, it appears likely that different $\mathrm{T}$ cell populations utilize the SL organelles to store and mobilize lineage-specific cargo proteins. However, the proteome of secretory lysosomes in $\mathrm{T}$ cells has not been deciphered. To provide the first proteome map for $\mathrm{T}$ cell-derived SL, we enriched organelles from activated $\mathrm{T}$ lymphoblasts. Organelle extracts were subjected to SDS-PAGE and Western blotting to identify the FasLcontaining SL fraction. This fraction was analyzed by electron microscopy to demonstrate the enrichment of a homogeneous population of intact vesicles. In order to define the luminal proteome of the respective SL compartment, the organelles were lysed and proteins were separated by 2D gel electrophoresis. Mass spectrometry was applied to identify individual spots. We annotated 397 proteins, $70 \%$ of which had been associated with lysosome-related organelles before. With the present report, we thus provide the first comprehensive description of the content of FasL-carrying effector vesicles isolated from activated human $\mathrm{T}$ lymphocytes.

\section{Results and Discussion}

In our preceding analysis of the SL compartment of NK cell lines and primary NK cells, we annotated 234 individual proteins and demonstrated a cell line-specific distribution of several functionally relevant molecules including cytotoxic effector proteins, lysosomal proteases and MHC molecules [12]. As a basis to address unsolved issues regarding the maturation, function and cell type-specific composition of the cytotoxic effector compartment in $\mathrm{T}$ cell populations, we now analyzed the proteome of enriched secretory lysosomes from in vitro activated human $\mathrm{T}$ cell blasts.

\section{FasL-associated secretory lysosomes in activated lymphocytes}

We and others have shown that in CTLs, preformed FasL accumulates in the limiting membrane of secretory lysosomes with late endosome or multi-vesicular-body structure and there co-localizes with characteristic lysosomal marker proteins including CD63 or lysosomal hydrolases and cytoskeletal adapter proteins [7-9,13-15]. Confocal laser-scanning microscopy (CLSM) was applied to confirm that FasL also might serve as a marker for secretory lysosomes in in vitro expanded PHA-stimulated $\mathrm{T}$ lymphocytes used in the present study. As depicted in Figure 1, we detected an apparent co-localization of CD63 with FasL, granzyme $A$ and the

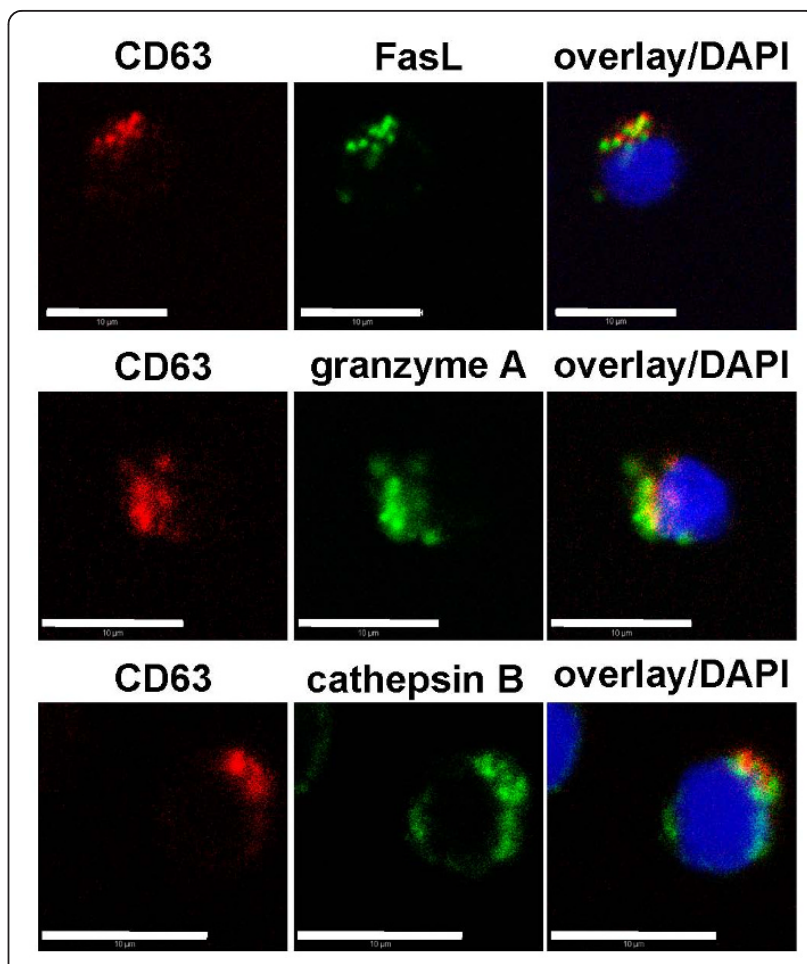

Figure 1 In T cell blasts, FasL associates with lysosomal vesicles. PHA blasts (d14) were fixed and stained for FasL with NOK1 and Alexa Fluor488-conjugated donkey anti-mouse IgG or for granzyme A with GrA-11 FITC-conjugated mAbs or for cathepsin B with polyclonal goat anti-cathepsin B (N-19) antibodies and Alexa Fluor488-conjugated donkey anti-goat IgG. After extensive washing, all samples were stained for CD63 with Alexa Fluor555-conjugated mAb MEM-259. Nuclei were visualized by DAPI (bar: $10 \mu \mathrm{m})$.

lysosomal protease cathepsin B. It should be mentioned that a common or distinct localization of LAMP-3 (CD63) and FasL is still controversially discussed. Several reports suggest a co-localization of FasL with granule proteins, such as cathepsin D, CD63, granzyme B, perforin and LAMP-1 in a single granular entity $[8,9]$ whereas other studies indicate that CD63 and FasL are located in distinct subcellular compartments [16].

Our protocol for the enrichment of secretory lysosomes yielded six separate fractions that were subjected to further analysis by Western blotting or 2D gel electrophoresis. To demonstrate an effective enrichment of the SL fraction, we first separated the proteins of individual fractions by SDS-PAGE and stained for characteristic organelle marker proteins after Western blotting. As shown in Figure 2, indicated by the high abundance of FasL, CD63 and cathepsin D, SL were enriched in fraction 2. Although LAMP-1 was also enriched in this fraction, the presence of this lysosomal membrane protein in other fractions might indicate the complex composition of the lysosomal compartment in general and that other lysosome-related vesicles might exist with distinct 


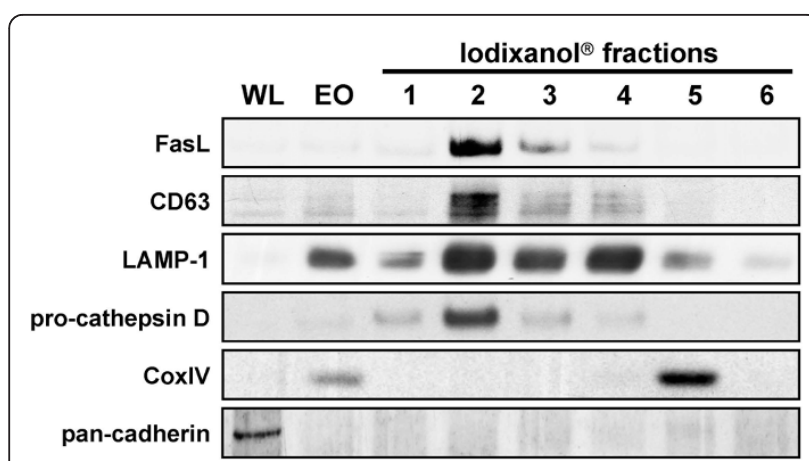

Figure 2 Western blot analysis of subcellular fractions Individual lanes represent whole cell lysate (WL), enriched organelles (EO) and the six fractions collected after density gradient centrifugation of IL-2 expanded T lymphocytes. The blots were probed with antibodies against respective markers for lysosomal (CD63, LAMP-1, cathepsin D) and secretory organelles (FasL). Pancadherin served as a marker for plasma membranes, CoxIV for mitochondria.

biophysical properties that separate at different media densities. As further indicators for the effective organelle enrichment and separation, we used cytochrome oxidase subunit IV (CoxIV) as a marker for mitochondria (see enriched organelles and fraction 5 in Figure 2) and pancadherin as a marker for the plasma membrane (only present in whole cell lysates). Of note, all proteins that were enriched in separate fractions were of course also present in the enriched organelle (EO) fraction placed on the gradient. However, due to the the relatively low abundance of individual proteins in the EO fraction, Western blot detection at the displayed exposure time did only reveal very faint bands. This is in agreement with our previous report [11] in which we showed a massive enrichment of FasL in fraction 2 while in the starting EO material from different $\mathrm{T}$ cell populations, FasL was almost not detectable at the same exposure time.

Regarding the "purity" of the obtained fraction, it should be stressed that most if not all enrichment protocols published so far do not allow a "purification" rather than an "enrichment" of a given organelle population. This is presumably based on the fact that lysosome formation and protein loading is a highly dynamic process that implies fusion and fission of several membraneous compartments and a complex protein sorting and transport machinery. For the initial characterization of enriched SL [11], we already pointed to potential "contaminations" in fraction 2, using antibodies against EEA1, a putative marker for endosomes, or Bip/Grp78, a marker for ER, respectively. Interestingly, during these analyses, golgin, a marker for the golgi apparatus/cisternae was only detected in fractions $3-6$, but not in fractions 1 and 2 [11]. For the present study, we thus restricted ourselves to routinely check for the marker proteins depicted in Figure 2.

\section{The enriched SL fraction consists of homogeneous intact vesicles}

In addition to the biochemical analysis of the individual fractions, we visualized the obtained lysosomal fraction 2 by electron microscopy in comparison to the putative mitochondrial fraction 5. Figure 3 provides characteristic overview pictures of the two fractions. In both cases, the organelles within one fraction display a high degree of homogeneity with respect to their morphology (Figure $3 \mathrm{~A}, \mathrm{C})$. At higher magnification, the characteristics of the organelles in fraction 2 become apparent. These membranous vesicles are round-shaped with a maximum size of about $700 \mathrm{~nm}$ and display a characteristic electron density. In contrast, organelles of fraction 5 are characterized by irregular internal membranous structures (Figure 3B,D) as expected for mitochondria.

\section{The luminal proteome of enriched SL as analyzed by 2D-} PAGE and mass spectrometry

In order to obtain a comprehensive list of putative luminal proteins of secretory lysosomes, enriched fraction 2 vesicles of PHA-stimulated T lymphoblasts were subjected to 2D-PAGE. More than 1600 spots from 6 replicate gels were subsequently subjected to proteolytic
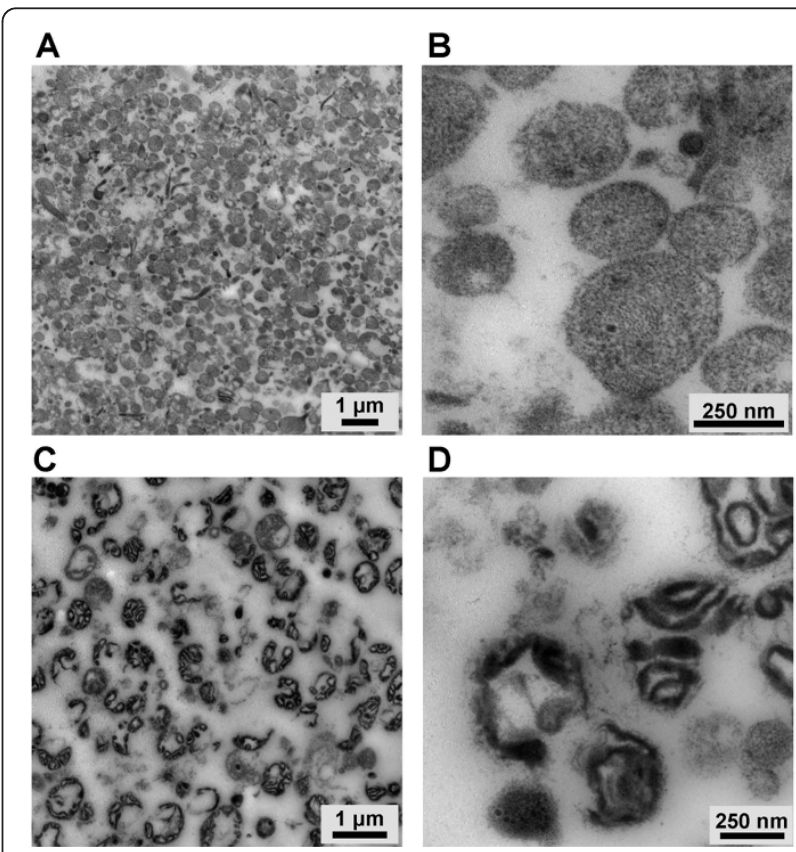

Figure 3 Electron micrographs of fractions 2 and $\mathbf{5}$. Enriched organelles from PHA blasts corresponding to fractions 2 (A, B) and 5 (C, D) were examined under an electron microscope. Overview pictures are given in $\mathrm{A}$ and $\mathrm{C}$, magnified areas are shown in $\mathrm{B}$ and D. (scale as indicated). 
cleavage and lead to the mass spectrometric identification of 1335 spots. Due to repetitive identifications at respective spot locations in different gels, the actual number of identified individual spots decreased to 742 . The resulting proteome map is shown as an overview in Figure 4. Additional information on identified proteins and images of individual quadrants to match proteins to respective spots are given as additional files 1, 2 and 3 (Table S1, FigureS1, Dataset S1). Multiple (up to six) identifications in separate gels from individual secretory lysosomes preparations from $\mathrm{T}$ cells of different donors also underscore the reproducibility of the isolation protocol [11]. Overall, the identified spots represent a total of 397 separate protein entries in the NCBI database that are listed according to their protein names, the predicted subcellular distribution and function in Table 1. Importantly, based on database annotations combining proteome analyses of different organelles [17], 70\% of the 397 proteins were assigned to lysosomal or secretory vesicles (including cytolytic granules (CG), lysosomes (LY), exosomes (EX), endosomes (EN), melanosomes (ME), platelet granules (PL) and synaptosomes (SY)) (Table 1, Figure 5). The majority of the remaining 30\% was classified as proteins of unknown (11\%) or cytosolic (11\%) localization, and as cytosolic or nuclear proteins (CY/NU, 3.5\%). The low percentage of mitochondrial (MT, 1.5\%), nuclear (NU, 0.8\%), plasma membrane (PM, $0.3 \%$ ) or endoplasmic strictly reticulum-associated

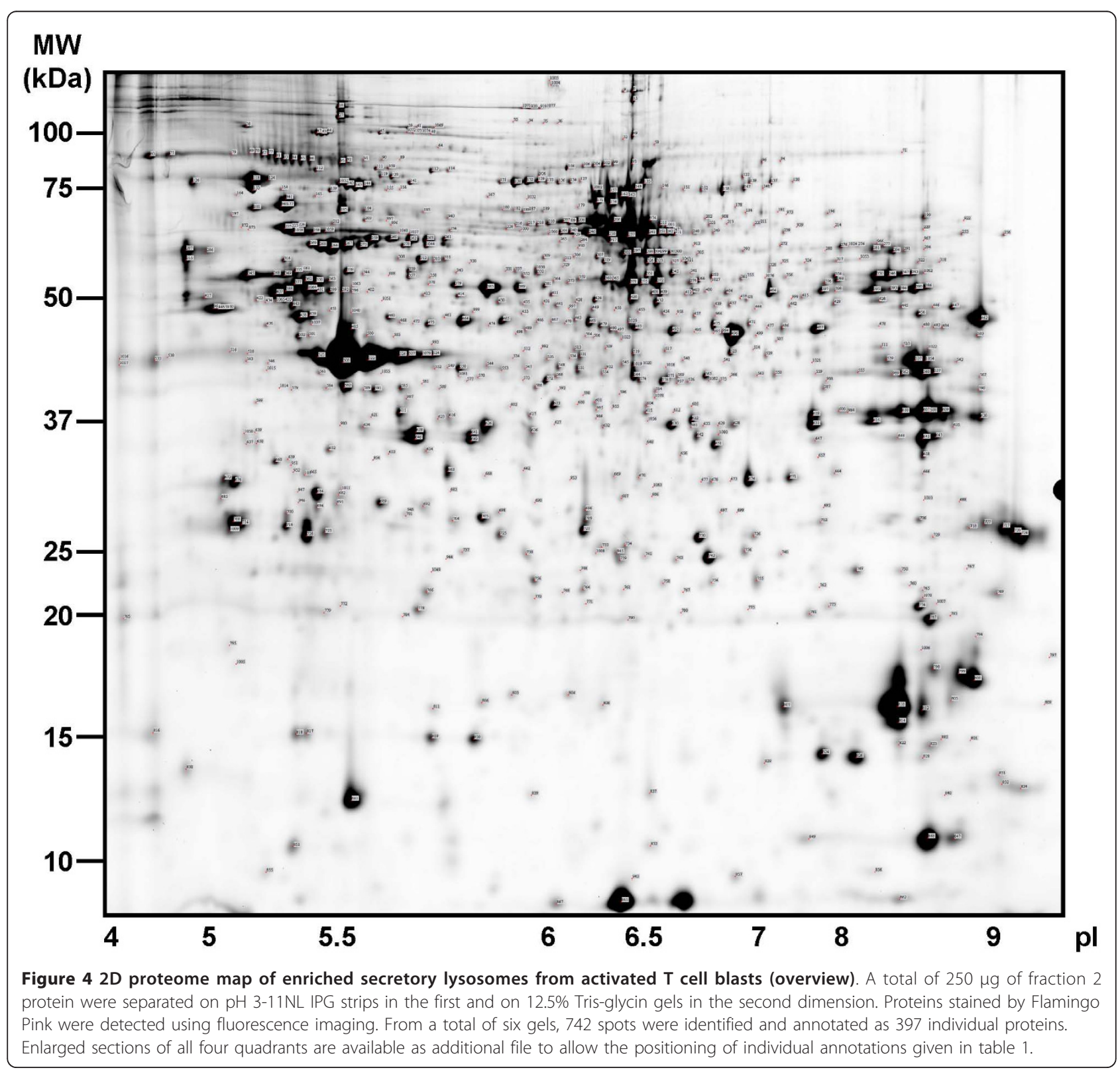


Table 1 Proteins identified in enriched secretory lysosomes from activated $\mathrm{T}$ cells

\begin{tabular}{|c|c|c|c|}
\hline Protein name & $\begin{array}{c}\text { Spot } \\
\#\end{array}$ & $\begin{array}{l}\text { Predicted/annotated subcellular } \\
\text { localisation }\end{array}$ & $\begin{array}{l}\text { Predicted } \\
\text { function }\end{array}$ \\
\hline 100 kDa coactivator & 122 & $\mathrm{ER}, \mathrm{ME}, \mathrm{PL}$ & biosynthesis \\
\hline 14-3-3 protein beta & 714 & $\mathrm{CY}, \mathrm{ME}$ & adapter \\
\hline 14-3-3 protein epsilon & 685 & $\mathrm{CY}, \mathrm{ME}$ & adapter \\
\hline 14-3-3 protein zeta/delta & 708 & CY,ME & adapter \\
\hline 2',3'-cyclic-nucleotide 3'-phosphodiesterase & 542 & $\mathrm{ME}, \mathrm{NG}$ & hydrolase \\
\hline $26 \mathrm{~S}$ protease regulatory subunit $6 \mathrm{~A}$ & 1037 & $\mathrm{CY}, \mathrm{NU}$ & $\begin{array}{l}\text { protein } \\
\text { degradation }\end{array}$ \\
\hline 265 proteasome non-ATPase regulatory subunit 2 & 165 & ME & proteasome \\
\hline 3-phosphoglycerate dehydrogenase & 408 & ME & biosythesis \\
\hline acetyl-CoA acetyltransferase, cytosolic & 594 & CY & biosynthesis \\
\hline ACTB protein & 525 & ER,ME,EX,PL,SY & cell motility \\
\hline actin related protein 2 isoform b & 564 & EN,ER,ME & trafficking \\
\hline actin related protein $2 / 3$ complex subunit $1 \mathrm{~B}$ & 590 & $\mathrm{ME}, \mathrm{PL}$ & trafficking \\
\hline actin related protein $2 / 3$ complex subunit 2 & 674 & EN,ME,PL,ER & trafficking \\
\hline actin related protein $2 / 3$ complex subunit 3 & 799 & $E N, M E, P L, E R$ & trafficking \\
\hline actin related protein $2 / 3$ complex subunit 4 & 798 & $E R, E X, M E, S Y$ & trafficking \\
\hline actin related protein $2 / 3$ complex subunit 5 -like & 804 & ME & trafficking \\
\hline actin, alpha, cardiac muscle & 570 & ME & cell motility \\
\hline actin, gamma 1 propeptide & 701 & $\mathrm{ME}, \mathrm{EX}, \mathrm{PL}, \mathrm{SY}$ & cell motility \\
\hline actinin, alpha 4 & 144 & $M E, N U, C Y$ & cell motility \\
\hline acylamino acid-releasing enzyme & 203 & $P L, C Y$ & hydrolase \\
\hline acyl-CoA synthetase long-chain family member 4 isoform 2 & 199 & MT,PE,ME & metabolism \\
\hline adenine phosphoribosyltransferase isoform b & 784 & $M E, E X, P L$ & biosynthesis \\
\hline adenosine deaminase & 550 & $C Y, L Y$ & hydrolase \\
\hline adenylosuccinate lyase & 439 & $C Y, P L$ & biosynthesis \\
\hline adenylosuccinate synthetase & 1023 & CY & biosynthesis \\
\hline adenylyl cyclase-associated protein variant & 395 & PL,ME & trafficking \\
\hline aflatoxin aldehyde reductase AFAR & 1056 & $\mathrm{PL}, \mathrm{GO}$ & redox protein \\
\hline aging-associated gene 12 & 418 & unknown & unclassified \\
\hline alanyl-tRNA synthetase & 111 & $\mathrm{ME}, \mathrm{PL}$ & biosynthesis \\
\hline alcohol dehydrogenase class-3 & 587 & $\mathrm{PL}, \mathrm{CY}$ & redox protein \\
\hline aldo-keto reductase family 1 , member $\mathrm{A} 1$ & 1078 & $\mathrm{PL}, \mathrm{SY}$ & metabolism \\
\hline aldolase A & 560 & EN,ME & metabolism \\
\hline aldose 1-epimerase (BLOCK25) & 596 & CY & metabolism \\
\hline aldose reductase & 981 & ME,EX,MT & metabolism \\
\hline alkyldihydroxyacetonephosphate synthase, peroxisomal & 273 & $P E$ & biosynthesis \\
\hline alpha-tubulin & 362 & $P L$ & cell motility \\
\hline annexin A1 & 615 & ME,MT & trafficking \\
\hline annexin A11 & 415 & MT,EX,ME & trafficking \\
\hline annexin A2 & 631 & MT,EX,ME,secreted & exocytosis \\
\hline annexin A4 & 668 & $M T, E X, M E, S Y$ & signal trans. \\
\hline annexin A5 & 660 & $M T, E X, M E, E R$ & trafficking \\
\hline annexin A6 & 263 & $M T, E X, M E, E R$ & trafficking \\
\hline annexin A7 isoform 2 & 504 & EX,ME,PL & exocytosis \\
\hline ARP3 actin-related protein 3 homolog & 465 & EN,ER,ME & trafficking \\
\hline ARTS-1 & 136 & $\mathrm{ER}, \mathrm{ME}$ & immunity \\
\hline aryl hydrocarbon receptor interacting protein & 955 & unknown & unclassified \\
\hline asparaginyl-tRNA synthetase & 306 & ME & biosynthesis \\
\hline aspartate aminotransferase & 575 & CY & biosynthesis \\
\hline ATP citrate lyase & 96 & $M E, E X, P L$ & biosynthesis \\
\hline ATP synthase, alpha subunit precursor & 426 & $E R, L Y, N G, S Y, M T$ & channel \\
\hline
\end{tabular}


Table 1 Proteins identified in enriched secretory lysosomes from activated $\mathbf{T}$ cells (Continued)

\begin{tabular}{|c|c|c|c|}
\hline ATPase, $\mathrm{H}+$ transporting, lysosomal $56 / 58 \mathrm{kDa}$, V1 subunit B2 & 413 & LY,ME,NG,SY & channel \\
\hline axin interactor, dorsalization associated protein & 632 & unknown & signal trans. \\
\hline beta adrenergic receptor kinase 1 & 220 & CY & GTPase \\
\hline bifunctional purine biosynthesis protein PURH & 326 & $\mathrm{ME}, \mathrm{PL}$ & mutifunctional \\
\hline bleomycin hydrolase & 463 & $C Y, P L$ & hydrolase \\
\hline BolA-like protein 2 & 867 & ME & unclassified \\
\hline calcium binding protein 39 & 622 & EX & unclassified \\
\hline CALM3 protein & 816 & unknown & unclassified \\
\hline calreticulin precursor variant & 287 & ER,ME,NG,EX,PL,MT & chaperone \\
\hline carboxyl terminal LIM domain protein & 612 & $\mathrm{ER}, \mathrm{ME}, \mathrm{PL}, \mathrm{EN}$ & cell motility \\
\hline catalase & 361 & $P E, E R, L Y, E N, M E$ & metabolism \\
\hline cathepsin B & 691 & LY,ME,NG & hydrolase \\
\hline cathepsin D preproprotein & 696 & LY,ME,NG,EX,MT & hydrolase \\
\hline cathepsin $\mathrm{H}$ & 738 & LY & hydrolase \\
\hline cathepsin S & 749 & LY & immunity \\
\hline Cbr1 In Complex With Hydroxy-Pp & 666 & ME & redox protein \\
\hline Cdc42ACK GTPASE & 790 & ME & cell motility \\
\hline centaurin beta1 & 214 & unknown & GTPase \\
\hline chaperonin (HSP60) & 338 & ME,NG,EX,SY,MT & chaperone \\
\hline chaperonin containing TCP1, subunit $2 \beta$ & 424 & ER,EN,ME,PL,MT,CY & chaperone \\
\hline chaperonin containing TCP1, subunit $7 \eta$ & 376 & EN,ME,PL & chaperone \\
\hline chaperonin containing TCP1, subunti $5 \varepsilon$ & 339 & EX,PL & chaperone \\
\hline chaperonin containing TCP1, subunti $8 \tau$ & 357 & EN,ME,EX & chaperone \\
\hline chaperonin containing TCP1, subunti $8 \tau$ & 358 & EN,ME,EX & chaperone \\
\hline chromatin modifying protein $4 B$ & 639 & $\mathrm{ME}, \mathrm{EX}$ & trafficking \\
\hline chromosome 20 open reading frame 3 (BSCV) & 489 & ME & unclassified \\
\hline chromosome 9 open reading frame 19 & 831 & $\mathrm{EX}, \mathrm{GO}$ & unclassified \\
\hline N2 protein & 651 & unknown & unclassified \\
\hline coactosin-like protein & 841 & PL,SY & unclassified \\
\hline cofilin 1 & 810 & ER,ME,EX,MT & cell motility \\
\hline copine I & 310 & ME & trafficking \\
\hline copine III & 340 & $\mathrm{ME}, \mathrm{EX}, \mathrm{PL}$ & trafficking \\
\hline coronin 7 & 113 & $\mathrm{CY}, \mathrm{GO}$ & trafficking \\
\hline coronin, actin binding protein, $1 \mathrm{~A}$ & 371 & LY,PL & cell motility \\
\hline coronin, actin binding protein, $1 \mathrm{C}$ & 353 & ME & multifunctional \\
\hline c-src tyrosine kinase & 475 & CY,PL & signal trans. \\
\hline cyclophilin A & 826 & $M E, E X, M T$ & chaperone \\
\hline cyclophilin B & 800 & ER,ME & chaperone \\
\hline cystatin B & 857 & ME & protein inhibitor \\
\hline cysteine and glycine-rich protein 1 & 769 & NU & unclassified \\
\hline cytoskeleton associated protein & 952 & CY & cell motility \\
\hline cytosolic malate dehydrogenase & 642 & ME,EX,PL,SY,MT & metabolism \\
\hline DCHT2 Serine/threonine-protein kinase OSR1 & 332 & ME & signal trans. \\
\hline destrin isoform a & 814 & $M E, E X, M T$ & cell motility \\
\hline differentially expressed in FDCP 6 homolog (mouse), isoform CRA_b & 228 & unknown & unclassified \\
\hline dihydropyrimidinase-like 2 & 319 & SY & signal trans. \\
\hline dimethylarginine dimethylaminohydrolase 2 & 683 & unknown & hydrolase \\
\hline dipeptidyl peptidase 4 & 81 & $E R, L Y, E N, M E, E X$ & hydrolase \\
\hline DJ-1 protein & 764 & $M E, P L, S Y, M T$ & redox protein \\
\hline DnaJ (Hsp40) homolog, subfamily A, member 1, isoform CRA_d & 499 & ER,ME & chaperone \\
\hline DnaJ (Hsp40) homolog, subfamily B, member 11 precursor & 551 & ER & chaperone \\
\hline docking protein 2 & 455 & unknown & unclassified \\
\hline
\end{tabular}


Table 1 Proteins identified in enriched secretory lysosomes from activated $\mathbf{T}$ cells (Continued)

\begin{tabular}{|c|c|c|c|}
\hline dynamin 2 isoform 1 & 148 & EN & trafficking \\
\hline echinoderm microtubule associated protein like 2 variant & 929 & CY & cell motility \\
\hline EF-hand domain family, member D2 & 1012 & unknown & unclassified \\
\hline EH-domain containing 1 & 342 & ER,LY,EN,EX,PL & trafficking \\
\hline Ena-VASP-like protein & 447 & CY & cell motility \\
\hline ENC-1AS aka Beta-hexosaminidase subunit beta & 431 & LY & multifunctional \\
\hline endoplasmic reticulum protein 29 isoform 1 precursor & 721 & $\mathrm{ER}, \mathrm{ME}, \mathrm{PL}$ & chaperone \\
\hline enolase 1 variant & 496 & ME,EX,SY,MT & metabolism \\
\hline ERAP2 protein & 99 & ER & immunity \\
\hline ERBB2IP protein & 197 & $\mathrm{NU}, \mathrm{CY}$ & multifunctional \\
\hline ERO1L & 311 & $\mathrm{ME}, \mathrm{ER}$ & redox protein \\
\hline esterase D/formylglutathione hydrolase & 656 & ME & hydrolase \\
\hline eukaryotic translation elongation factor 1 alpha 1 & 462 & $E R, L Y, E N, M E, E X, P L$ & biosynthesis \\
\hline eukaryotic translation elongation factor 1 gamma, isoform CRA_d & 947 & ME & biosynthesis \\
\hline eukaryotic translation elongation factor 2 & 158 & $E R, E N, M E, E X$ & biosynthesis \\
\hline eukaryotic translation initiation factor $4 \mathrm{~A}$ & 505 & ME & biosynthesis \\
\hline eukaryotic translation initiation factor $5 \mathrm{~A}$ & 817 & ME & biosynthesis \\
\hline extended-synaptotagmin-1 KIAA0747 protein & 155 & ME & unclassified \\
\hline ezrin & 208 & $C Y$ & cell motility \\
\hline F-actin capping protein alpha-1 subunit & 611 & ER,EN,ME & actin binding \\
\hline F-actin capping protein alpha-1 subunit variant & 623 & ER,EN,ME & actin binding \\
\hline F-actin capping protein alpha-2 subunit & 616 & $\mathrm{ER}, \mathrm{EN}, \mathrm{ME}, \mathrm{PL}$ & cell motility \\
\hline F-actin capping protein beta subunit & 663 & ER,EN,ME & actin binding \\
\hline farnesyl pyrophosphate synthetase & 579 & $\mathrm{CY}$ & biosynthesis \\
\hline FK506 binding protein $1 \mathrm{~A}$ & 856 & ME,SY,MT & signal trans. \\
\hline flotillin 1 & 486 & LY,ME,EX & membrane \\
\hline formin-binding protein 1 & 1059 & $S L, L Y, C Y$ & adapter \\
\hline fructose-bisphosphate aldolase $C$ & 565 & ME,SY,MT & metabolism \\
\hline fumarate hydratase, mitochondrial & 507 & EN,SY,MT & cell cycle \\
\hline FYN-binding protein & 71 & CY,NU & adapter \\
\hline $\mathrm{G}$ protein beta subunit & 638 & ME,MT & signal trans. \\
\hline galectin-1 & 851 & ME,PL & immunity \\
\hline galectin-3 & 718 & $\mathrm{ME}, \mathrm{NU}$ & immunity \\
\hline gamma-enolase & 476 & $M E, P L, S Y$ & glycolysis \\
\hline gamma-glutamyl hydrolase & 629 & $L Y, M E, N G, P L$ & hydrolase \\
\hline GDP-mannose pyrophosphorylase A & 541 & unknown & biosythesis \\
\hline gelsolin-like capping protein isoform 9 & 572 & $\mathrm{ME}, \mathrm{CY}, \mathrm{NU}$ & cell motility \\
\hline GIPC1 protein & 598 & $S Y, C Y$ & protein binding \\
\hline glia maturation factor gamma & 818 & unknown & unclassified \\
\hline glucosamine-6-phosphate deaminase 1 & 677 & CY & hydrolase \\
\hline glucose-6-phosphate dehydrogenase isoform b & 409 & ME & metabolism \\
\hline glucosidase II subunit beta & 126 & $E R, M E, P L$ & hydrolase \\
\hline glucosidase, alpha; neutral AB, isoform CRA_a & 936 & $E R, M E, P L$ & hydrolase \\
\hline glutamate carboxypeptidase & 430 & unknown & hydrolase \\
\hline glutamate Dehydrogenase-Apo Form & 437 & ER,ME,PL,MT & unclassified \\
\hline glutaredoxin 3 & 589 & CY & redox protein \\
\hline glutathione S-transferase P1 & 766 & $\mathrm{ER}, \mathrm{ME}, \mathrm{EX}, \mathrm{PL}$ & metabolism \\
\hline glutathione synthetase & 461 & $\mathrm{PL}$ & redox protein \\
\hline glutathione-S-transferase kappa 1 & 765 & PL,ME,MT,PE & unclassified \\
\hline glutathione-S-transferase omega 1 & 698 & LY,ME,NG,EX,PL,SY,MT & metabolism \\
\hline glyceraldehyde-3-phosphate dehydrogenase & 610 & LY,ME,NG,EX,PL,SY,MT & metabolism \\
\hline glycyl-tRNA synthetase & 244 & ME & biosynthesis \\
\hline
\end{tabular}


Table 1 Proteins identified in enriched secretory lysosomes from activated $\mathbf{T}$ cells (Continued)

\begin{tabular}{|c|c|c|c|}
\hline glyoxalase domain containing 4 & 653 & MT & unclassified \\
\hline GNAS complex locus isoform $f$ & 531 & EX & multifunctional \\
\hline GNB1 protein & 634 & EN,ME,EX,PL,SY & signal trans. \\
\hline granzyme A & 724 & SL & immunity \\
\hline GRAP2 protein & 957 & unknown & unclassified \\
\hline GRB2 protein & 756 & SY & adapter \\
\hline GTP-binding nuclear protein Ran & 755 & $\mathrm{ME}, \mathrm{EX}$ & trafficking \\
\hline $\begin{array}{l}\text { guanine nucleotide binding protein (G protein), alpha inhibiting activity } \\
\text { polypeptide } 2 \text {, isoform CRA_c }\end{array}$ & 582 & EX & GTPase \\
\hline $\begin{array}{l}\text { guanine nucleotide binding protein (G protein), beta polypeptide 2-like 1, isoform } \\
\text { CRA_d }\end{array}$ & 664 & ER & signal trans. \\
\hline guanine nucleotide-binding protein $G(k)$ subunit alpha & 585 & ME,EX & trafficking \\
\hline guanine nucleotide-binding protein subunit alpha-13 & 989 & ME & signal trans. \\
\hline haloacid dehalogenase-like hydrolase domain containing 2 & 690 & unknown & hydrolase \\
\hline heat shock $70 \mathrm{kDa}$ protein $1 \mathrm{~A}$ & 278 & ER,EN,ME,EX,MT & chaperone \\
\hline heat shock $70 \mathrm{kDa}$ protein 5 & 226 & $\mathrm{ER}, \mathrm{ME}, \mathrm{EX}, \mathrm{PL}, \mathrm{MT}$ & chaperone \\
\hline heat shock 70kDa protein 8 isoform 1 & 259 & $L Y, M E, N G, E X, P L, S Y, M T$ & chaperone \\
\hline heat shock 70kDa protein 8 isoform 1 & 260 & $L Y, M E, N G, E X, P L, S Y, M T$ & chaperone \\
\hline heat shock protein 70 & 112 & EX & chaperone \\
\hline heat shock protein HSP 90-alpha & 969 & $\mathrm{ME}, \mathrm{NG}, \mathrm{MT}$ & chaperone \\
\hline heat shock protein HSP 90-beta & 177 & ME,EX,MT & chaperone \\
\hline hematopoietic cell-specific Lyn substrate 1 & 181 & $\mathrm{CY}, \mathrm{MT}$ & signal trans. \\
\hline HEXA protein & 422 & LY & multifunctional \\
\hline hexose-6-phosphate dehydrogenase & 194 & ER & metabolism \\
\hline HIP-55 & 377 & $C Y$ & signal trans. \\
\hline histidine triad nucleotide binding protein 1 & 852 & $M E, P L, S Y$ & hydrolase \\
\hline histocompatibility (minor) $\mathrm{HA}-1$ & 1072 & unknown & GTPase \\
\hline hypothetical protein & 216 & unknown & unclassified \\
\hline hypothetical protein LOC79624 & 472 & unknown & unclassified \\
\hline hypoxia up-regulated protein 1 & 47 & ER,PL,ME & chaperone \\
\hline importin subunit beta-1 & 164 & ME & trafficking \\
\hline integrin beta-2 & 80 & $\mathrm{PL}$ & membrane \\
\hline interleukin-16 & 210 & secreted & immunity \\
\hline isocitrate dehydrogenase $1(\mathrm{NADP}+)$, soluble, isoform CRA_b & 540 & $M E, E X, P L$ & redox protein \\
\hline isocitrate dehydrogenase $2(\mathrm{NADP}+)$, mitochondrial, isoform CRA_b & 510 & PL,MT & redox protein \\
\hline kinase/transmembrane domain fusion protein & 1061 & unknown & unclassified \\
\hline laminin-binding protein & 543 & $M E, E R$ & cell adhesion \\
\hline leucine aminopeptidase 3 & 432 & $\mathrm{CY}$ & $\begin{array}{l}\text { protein } \\
\text { degradation }\end{array}$ \\
\hline leucine rich repeat containing 57 & 747 & unknown & unclassified \\
\hline leucine-rich repeat and calponin homology domain-containing protein 5 & 908 & MT & protein binding \\
\hline leucocyte antigen CD97 & 872 & ME,secreted & cell adhesion \\
\hline leukocyte-derived arginine aminopeptidase long form variant & 102 & unknown & hydrolase \\
\hline leukotriene A4 hydrolase & 309 & CY & hydrolase \\
\hline LIM and SH3 domain protein 1 & 606 & $\mathrm{ER}, \mathrm{EN}, \mathrm{ME}, \mathrm{PL}$ & adapter \\
\hline LIM domain-containing protein 2 & 834 & unknown & unclassified \\
\hline lin 7 homolog c & 1070 & SY & exocytosis \\
\hline L-lactate dehydrogenase & 645 & $\mathrm{ME}, \mathrm{EX}, \mathrm{SY}$ & metabolism \\
\hline L-lactate dehydrogenase B chain & 626 & ME,EX,PL,SY,MT & redox protein \\
\hline L-plastin & 266 & CY & actin binding \\
\hline L-plastin variant & 267 & unknown & cell motility \\
\hline LPXN protein & 474 & unknown & unclassified \\
\hline lymphocyte cytosolic protein 2 & 229 & CY & immunity \\
\hline
\end{tabular}


Table 1 Proteins identified in enriched secretory lysosomes from activated $\mathbf{T}$ cells (Continued)

\begin{tabular}{|c|c|c|c|}
\hline lymphocyte-specific protein 1 & 959 & $\mathrm{PL}$ & immunity \\
\hline lysosomal acid alpha-mannosidase & 265 & LY,ME & hydrolase \\
\hline M2-type pyruvate kinase & 356 & $M E, E X, S Y$ & metabolism \\
\hline Macrophage Migration Inhibitory Factor (Mif) With Hydroxphenylpyruvate & 862 & $M E, E X, P L, S Y$ & immunity \\
\hline MAGUK p55 subfamily member 7 & 292 & $P L$ & protein binding \\
\hline methylenetetrahydrofolate dehydrogenase 1 & 139 & EN,ME,PL,MT & multifunctional \\
\hline methylthioadenosine phosphorylase & 697 & CY & metabolism \\
\hline MHC class I antigen & 533 & ME & immunity \\
\hline MHC class I antigen & 865 & ME & immunity \\
\hline MHC class $\|$ antigen & 953 & ME & immunity \\
\hline MHC class II antigen DR alpha chain & 1050 & LY & immunity \\
\hline MHC class II antigen DR52 & 1083 & ME & immunity \\
\hline microtubule-associated protein, RP/EB family, member 1 & 665 & $\mathrm{ME}, \mathrm{PL}$ & cell motility \\
\hline mitochondrial ATP synthase, $\mathrm{H}+$ transporting F1 complex beta subunit & 443 & MT & trafficking \\
\hline mitochondrial trifunctional protein, alpha subunit precursor & 253 & $\mathrm{PL}, \mathrm{MT}$ & metabolism \\
\hline mitogen-activated protein kinase 1 & 569 & $\mathrm{ME}, \mathrm{PL}$ & signal trans. \\
\hline mitogen-activated protein kinase kinase 1 interacting protein 1 & 943 & LY & adapter \\
\hline mitogen-activated protein kinase kinase 2 & 509 & unknown & signal trans. \\
\hline moesin, isoform CRA_b & 246 & EN,ME,EX,PL,MT & cell motility \\
\hline mps one binder kinase activator-like $1 \mathrm{~B}$ & 758 & unknown & unclassified \\
\hline myosin IG & 75 & unknown & trafficking \\
\hline myosin light polypeptide 6 & 830 & ME & cell motility \\
\hline $\begin{array}{l}\text { NADH dehydrogenase (ubiquinone) Fe-S protein 1, } 75 \text { kDa (NADH-coenzyme Q } \\
\text { reductase) }\end{array}$ & 896 & ER,ME,MT & trafficking \\
\hline NCK adaptor protein 1 & 506 & CY,ER & adapter \\
\hline NECAP endocytosis associated 2 & 1010 & EN & trafficking \\
\hline NESH protein & 434 & unknown & unclassified \\
\hline $\mathrm{N}$-ethylmaleimide-sensitive factor attachment protein, alpha & 652 & ME,NG,PL & trafficking \\
\hline neuroblastoma RAS viral (v-ras) oncogene homolog & 779 & $\mathrm{GO}, \mathrm{CY}$ & trafficking \\
\hline neuropolypeptide h3 & 781 & $M E, E X, S Y$ & protein inhibitor \\
\hline neutrophil adherence receptor alpha-M subunit & 36 & membrane & cell adhesion \\
\hline niban protein isoform 2 & 38 & $\mathrm{CY}$ & signal trans. \\
\hline NME1-NME2 protein & 823 & $\mathrm{CY}, \mathrm{NU}$ & multifunctional \\
\hline nuclear chloride channel & 684 & $M E, E X, P L, M T$ & channel \\
\hline nucleobindin 1 variant & 335 & unknown & unclassified \\
\hline nucleoside phosphorylase & 670 & CY,PL & cell cycle \\
\hline nucleosome assembly protein 1-like 1, isoform CRA_d & 315 & $\mathrm{ME}, \mathrm{PL}, \mathrm{NU}$ & cell cycle \\
\hline Obg-like ATPase 1 & 511 & $\mathrm{EN}, \mathrm{ME}, \mathrm{PL}$ & hydrolase \\
\hline otubain 1 & 637 & ME & hydrolase \\
\hline PA2G4 protein & 490 & unknown & unclassified \\
\hline PDCD6IP protein & 171 & unknown & unclassified \\
\hline perforin-1 & 280 & SL & immunity \\
\hline peroxiredoxin 1 & 774 & $E R, L Y, E N, M E, N G, P L, M T$ & redox protein \\
\hline peroxiredoxin 2 & 778 & ER,EN,ME,SY,MT & redox protein \\
\hline peroxiredoxin 3 & 768 & ME,PL,MT & redox protein \\
\hline peroxiredoxin 4 & 737 & ER,EN,ME & redox protein \\
\hline peroxiredoxin 6 & 945 & LY,ME,EX,PL,SY & redox protein \\
\hline PGAM1 & 730 & $M E, E X, S Y$ & metabolism \\
\hline $\mathrm{PHB}$ & 948 & unknown & unclassified \\
\hline phosphatase $2 a$ & 316 & MT & multifunctional \\
\hline phosphatidylinositol-5-phosphate 4-kinase, type II, alpha & 457 & $N G, P L$ & metabolism \\
\hline phosphofructokinase, liver & 939 & unknown & glycolysis \\
\hline
\end{tabular}


Table 1 Proteins identified in enriched secretory lysosomes from activated $\mathbf{T}$ cells (Continued)

\begin{tabular}{|c|c|c|c|}
\hline phosphofructokinase, platelet & 196 & $\mathrm{ME}, \mathrm{PL}$ & glycolysis \\
\hline phosphoglucose isomerase & 390 & ME,EX,PL,MT & multifunctional \\
\hline phosphoglycerate kinase 1 & 537 & ME,EX,SY,MT & metabolism \\
\hline phospholipase C, delta 1 variant & 178 & unknown & signal trans. \\
\hline phosphoribosyl pyrophosphate synthetase 1 variant & 1080 & unknown & biosynthesis \\
\hline $\begin{array}{l}\text { phosphoribosylaminoimidazole carboxylase, - succinocarboxamide synthetase, } \\
\text { isoform CRA_b }\end{array}$ & 523 & EN,SY & multifunctional \\
\hline phosphoribosylformylglycinamidine synthase & 64 & $C Y$ & biosynthesis \\
\hline phosphoserine aminotransferase 1 & 988 & ME & biosynthesis \\
\hline phostensin & 91 & CY & unclassified \\
\hline poly(A) binding protein, cytoplasmic 1, isoform CRA_C & 256 & $\mathrm{ER}, \mathrm{EN}, \mathrm{ME}, \mathrm{PL}$ & metabolism \\
\hline poly $(\mathrm{rC})$ binding protein 1 & 1082 & $\mathrm{ME}, \mathrm{CY}, \mathrm{NU}$ & unclassified \\
\hline $\begin{array}{l}\text { potassium voltage-gated channel, shaker-related subfamily, beta member } 2 \text { isoform } \\
2\end{array}$ & 635 & CY & channel \\
\hline PPP5C protein & 364 & $\mathrm{CY}, \mathrm{NU}$ & hydrolase \\
\hline profilin-1 & 848 & $M E, E X, P L, M T$ & actin binding \\
\hline programmed cell death protein 10 & 741 & unknown & apoptosis \\
\hline proline synthetase co-transcribed homolog & 699 & CY & unclassified \\
\hline prolyl 4-hydroxylase, alpha subunit & 337 & ER,ME & redox protein \\
\hline prolyl 4-hydroxylase, beta subunit precursor & 348 & $\mathrm{ER}, \mathrm{ME}, \mathrm{EX}, \mathrm{PL}, \mathrm{MT}$ & redox protein \\
\hline prolyl endopeptidase & 234 & $\mathrm{CY}$ & $\begin{array}{l}\text { protein } \\
\text { degradation }\end{array}$ \\
\hline proteasome (prosome, macropain) subunit, alpha type, 7(PSMA7) & 729 & CY,Proteasom & hydrolase \\
\hline proteasome 265 non-ATPase subunit 13 isoform 1 & 577 & ME & proteasome \\
\hline proteasome $26 \mathrm{~S}$ subunit, ATPase, 2 & 498 & $\mathrm{CY}, \mathrm{NU}$ & unclassified \\
\hline proteasome $26 \mathrm{~S}$ subunit, ATPase, 5 & 514 & $\mathrm{CY}, \mathrm{NU}$ & unclassified \\
\hline proteasome activator complex subunit 1 isoform 1 & 703 & $\mathrm{PL}, \mathrm{MT}$ & immunity \\
\hline proteasome activator complex subunit 2 & 689 & ME & immunity \\
\hline proteasome alpha 2 subunit variant & 754 & CY & hydrolase \\
\hline proteasome subunit, alpha type, 1 & 687 & ME & hydrolase \\
\hline proteasome subunit, alpha type, 5 & 1009 & ME & hydrolase \\
\hline proteasome subunit, alpha type, 6 & 734 & $\mathrm{CY}, \mathrm{NU}$ & hydrolase \\
\hline proteasome subunit, beta type, 1 & 750 & $\mathrm{ME}, \mathrm{CY}$ & hydrolase \\
\hline proteasome subunit, beta type, 2 & 780 & $\mathrm{CY}, \mathrm{NU}$ & hydrolase \\
\hline proteasome subunit, beta type, 4 & 944 & $\mathrm{CY}, \mathrm{NU}$ & hydrolase \\
\hline proteasome subunit, beta type, 8 & 773 & PL,CY,NU & immunity \\
\hline protein ARMET & 805 & $M E$, secreted & unclassified \\
\hline protein diaphanous homolog 1 & 45 & ME & cell motility \\
\hline protein disulfide isomerase-associated 4 & 1060 & $E R, M E, P L$ & chaperone \\
\hline protein disulfide isomerase-related protein 5 & 458 & $\mathrm{ER}, \mathrm{ME}$ & chaperone \\
\hline protein disulfide-isomerase A3 & 379 & $E R, L Y, M E, N G, E X, P L$ & chaperone \\
\hline protein phosphatase 1 , catalytic subunit, alpha isoform 1 & 603 & EX & hydrolase \\
\hline protein phosphatase 1, catalytic subunit, beta isoform & 617 & ME,PL & hydrolase \\
\hline protein tyrosine phosphatase $1 \mathrm{~b}$ & 536 & $M E, E R$ & hydrolase \\
\hline protein tyrosine phosphatase, non-receptor type 6 isoform 1 variant & 317 & unknown & hydrolase \\
\hline protein-tyrosine kinase fyn isoform c & 373 & EN,CY & signal trans. \\
\hline PYD and CARD domain containing & 771 & CY & apoptosis \\
\hline pyrophosphatase 1 & 654 & ME,MT & hydrolase \\
\hline pyruvate kinase 3 isoform 2 & 346 & $M E, E X, S Y$ & metabolism \\
\hline R33729_1 (Interleukin-25) & 837 & ME,secreted & signal trans. \\
\hline Rab GDP dissociation inhibitor beta & 469 & ME,EX,PL,MT & GTPase \\
\hline raftlin cell migration-inducing gene 2 & 193 & $P L$ & unclassified \\
\hline Rap1a & 785 & EN,ME,MT & GTPase \\
\hline
\end{tabular}


Table 1 Proteins identified in enriched secretory lysosomes from activated $\mathbf{T}$ cells (Continued)

\begin{tabular}{|c|c|c|c|}
\hline Rap1-GTP-interacting adapter molecule & 141 & $\mathrm{CY}$ & signal trans. \\
\hline Ras GTPase-activating-like protein IQGAP2 & $1069 a$ & EN & signal trans. \\
\hline related RAS viral (r-ras) oncogene homolog 2 isoform a & 1049 & LY,ME,EX & GTPase \\
\hline Rho GDP dissociation inhibitor (GDI) alpha & 716 & ME,PL,MT & GTPase \\
\hline Rho GDP dissociation inhibitor (GDI) beta & 728 & CY & GTPase \\
\hline Rho GTPase activating protein 1 & 441 & $P L$ & GTPase \\
\hline Rho GTPase-activating protein 9 & 998 & unknown & GTPase \\
\hline ribosomal protein L11 & 797 & ribosome & biosynthesis \\
\hline ribosomal protein L12 & 809 & EN,ribosom & biosynthesis \\
\hline S-adenosylhomocysteine hydrolase & 513 & ME & hydrolase \\
\hline Sec23 homolog A & 221 & $\mathrm{ER}, \mathrm{ME}, \mathrm{PL}$ & trafficking \\
\hline Sec23B protein & 1001 & EN & trafficking \\
\hline septin 2 & 554 & $\mathrm{ME}, \mathrm{EX}, \mathrm{SY}$ & unclassified \\
\hline septin 7 & 484 & ME,PL,SY & unclassified \\
\hline septin-9 delta & 558 & ME & unclassified \\
\hline septin-9 gamma & 973 & ME & unclassified \\
\hline serine/threonine phosphatase 1 gamma & 985 & MT,SY & hydrolase \\
\hline serine/threonine-protein kinase PAK 2 & 352 & $P L$ & signal trans. \\
\hline serine/threonine-protein phosphatase $2 \mathrm{~A}$ catalytic subunit alpha isoform & 621 & MT & signal trans. \\
\hline serine/threonine-protein phosphatase $2 \mathrm{~A}$ regulatory subunit $\mathrm{B}$ & 592 & NU & signal trans. \\
\hline serpin peptidase inhibitor,clade B,member 1 & 548 & CY & protein inhibitor \\
\hline seryl-tRNA synthetase & 365 & $\mathrm{ME}, \mathrm{PL}$ & $\begin{array}{c}\text { tRNA } \\
\text { processing }\end{array}$ \\
\hline $\mathrm{SH} 2$ domain protein $1 \mathrm{~A}$ & 840 & CY & signal trans. \\
\hline SH3-containing protein, Endophilin-B1 & 1081 & $\mathrm{CY}, \mathrm{GO}, \mathrm{MT}$ & apoptosis \\
\hline SHUJUN-1 & 795 & CY & cell motility \\
\hline signal transducer and activator of transcription $1,91 \mathrm{kDa}$, isoform CRA_d & 188 & CY,NU & signal trans. \\
\hline similar to metallo-beta-lactamase superfamily protein & 686 & unknown & hydrolase \\
\hline small GTP binding protein Rac2, isoform CRA_C & 1006 & unknown & signal trans. \\
\hline soc-2 suppressor of clear homolog & 318 & CY & unclassified \\
\hline solute carrier family 9 (sodium/hydrogen exchanger), isoform 3 regulator 1 & 460 & $M E, E X, P L$ & scaffolding \\
\hline sorting nexin 17 & 421 & EN,ME,PL & trafficking \\
\hline sorting nexin 6 & 466 & CY & trafficking \\
\hline src kinase associated phosphoprotein 1 isoform 1 & 417 & $\mathrm{CY}, \mathrm{NU}$ & signal trans. \\
\hline stathmin 1/oncoprotein 18 & 820 & SY & cell motility \\
\hline stress-induced-phosphoprotein 1 (Hsp70/Hsp90-organizing protein) & $323 a$ & ME,PL,SY & chaperone \\
\hline stromal cell-derived factor 2-like 1 precursor & 767 & ER & unclassified \\
\hline superoxide dismutase 1 , soluble & 806 & $M E, E X, M T$ & redox protein \\
\hline syntaxin binding protein 1 & 305 & $\mathrm{ME}, \mathrm{NG}, \mathrm{EX}, \mathrm{PL}, \mathrm{SY}$ & trafficking \\
\hline syntaxin binding protein 2 & 302 & EX,PL & trafficking \\
\hline syntaxin binding protein 3 variant & 294 & ME,PL & trafficking \\
\hline talin-1 & 920 & EN,ME,PL & cell motility \\
\hline tapasin isoform 3 precursor & 495 & $\mathrm{ER}, \mathrm{ME}$ & immunity \\
\hline TC4 protein & 736 & NU & GTPase \\
\hline T-complex polypeptide 1 & 1030 & $\mathrm{ER}, \mathrm{EN}, \mathrm{ME}, \mathrm{EX}$ & chaperone \\
\hline T-complex protein 1 subunit gamma & 307 & CY & chaperone \\
\hline testin isoform 1 & 456 & unknown & unclassified \\
\hline thioredoxin domain-containing protein 4 precursor & 502 & $\mathrm{ER}, \mathrm{ME}, \mathrm{PL}$ & scaffolding \\
\hline transfer RNA-Trp synthetase & 411 & ME,PL & biosynthesis \\
\hline transgelin-2 & 787 & ME,MT & unclassified \\
\hline transketolase & 276 & $\mathrm{ME}, \mathrm{EN}$ & unclassified \\
\hline translocon-associated protein subunit delta & 811 & $M E, E R$ & trafficking \\
\hline
\end{tabular}


Table 1 Proteins identified in enriched secretory lysosomes from activated $\mathbf{T}$ cells (Continued)

\begin{tabular}{|c|c|c|c|}
\hline triosephosphate isomerase 1 & 742 & ME,EX,SY,MT & unclassified \\
\hline tripeptidyl-peptidase 1 & 992 & LY,ME,NG,PL,MT & $\begin{array}{c}\text { protein } \\
\text { degradation }\end{array}$ \\
\hline tropomodulin 3 & 561 & $\mathrm{ER}, \mathrm{ME}$ & cell motility \\
\hline tropomyosin 3 isoform 2 & 676 & unknown & unclassified \\
\hline tropomyosin 4 & 672 & $\mathrm{ME}$ & unclassified \\
\hline Tu translation elongation factor, mitochondrial & 517 & LY,ME,PL,MT & biosynthesis \\
\hline tubulin alpha 6 variant & 363 & $M E, P L$ & cell motility \\
\hline tubulin tyrosine ligase-like family, member 12 & 897 & ME & trafficking \\
\hline tubulin, beta & 407 & ME,PL,SY & cell motility \\
\hline tubulin, beta polypeptide & 433 & $\mathrm{ME}, \mathrm{PL}, \mathrm{SY}$ & cell motility \\
\hline tumor rejection antigen (gp96) 1 & 118 & $\mathrm{ER}, \mathrm{ME}, \mathrm{PL}, \mathrm{GO}$ & chaperone \\
\hline tumor susceptibility gene 101 & 470 & EX & trafficking \\
\hline tyrosine kinase LCK & 399 & CY & signal trans. \\
\hline tyrosine-protein phosphatase non-receptor type 6 & 325 & CY,NU & signal trans. \\
\hline tyrosyl-tRNA synthetase & 366 & $\mathrm{ME}, \mathrm{PL}$ & signal trans. \\
\hline ubiquitin associated and $\mathrm{SH} 3$ domain containing protein $\mathrm{A}$ & 913 & $\mathrm{CY}, \mathrm{NU}$ & $\begin{array}{c}\text { protein } \\
\text { degradation }\end{array}$ \\
\hline ubiquitin specific peptidase 5 isoform 2 & 154 & $L Y, M E, N G$ & $\begin{array}{c}\text { protein } \\
\text { degradation }\end{array}$ \\
\hline ubiquitin specific protease 14 isoform a & 344 & $\mathrm{PL}$ & $\begin{array}{c}\text { protein } \\
\text { degradation }\end{array}$ \\
\hline ubiquitin-conjugating enzyme E2 L3 & 882 & MT & $\begin{array}{c}\text { protein } \\
\text { degradation }\end{array}$ \\
\hline ubiquitin-conjugating enzyme E2 N & 839 & ME,EX,MT & differentiation \\
\hline ubiquitin-like modifier-activating enzyme 1 & 120 & MT,ME & $\begin{array}{c}\text { protein } \\
\text { degradation }\end{array}$ \\
\hline UDP-glucose pyrophosphorylase 2 isoform b & 442 & EN,ME & metabolism \\
\hline UNC-112 related protein 2 long form & 971 & $P L$ & cell adhesion \\
\hline unnamed protein product & 706 & unknown & unclassified \\
\hline UPF0550 protein C7orf28 & 450 & ME & unclassified \\
\hline vacuolar H+-ATPase 56,000 subunit & 414 & LY,ME,NG,SY & channel \\
\hline vacuolar protein sorting 45A & 322 & LY,EN & trafficking \\
\hline vacuolar sorting protein 33A & 1067 & $E N, L Y$ & trafficking \\
\hline valosin-containing protein & 159 & unknown & unclassified \\
\hline vasodilator-stimulated phosphoprotein & 503 & $P L$ & cell motility \\
\hline vinculin & 108 & $\mathrm{ME}$ & cell motility \\
\hline voltage-dependent anion channel 1 & 658 & $\mathrm{ER}, \mathrm{LY}, \mathrm{ME}, \mathrm{NG}, \mathrm{EX}, \mathrm{PL}, \mathrm{SY}, \mathrm{MT}$ & channel \\
\hline voltage-dependent anion channel 2 & 657 & SY,MT & channel \\
\hline voltage-dependent anion channel 3 & 688 & EN,ME,MT & channel \\
\hline V-type proton ATPase subunit d 1 & 599 & LY,EN,ME,SY & channel \\
\hline WD repeat domain 1 & 304 & $\mathrm{EN}, \mathrm{ME}, \mathrm{EX}$ & cell motility \\
\hline Wiskott-Aldrich syndrome protein & $323 b$ & $\mathrm{CY}$ & cell motility \\
\hline XRP2 protein & 546 & ME & signal trans. \\
\hline zeta-chain associated protein kinase $70 \mathrm{kDa}$ & 277 & CY & signal trans. \\
\hline
\end{tabular}

397 individual proteins were identified to be associated with enriched secretory lysosomes from human T cell blasts. The proteins are listed by name, followed by individual spot numbers and the predicted/annotated subcellular localisation and function. Abbreviations: LY: lysosomes, ME: melanosomes, PL: platelet granules, SY: synaptosomes, EX: exosomes, CG: cytotoxic granules, NG: neuromelanin granules, EN: endosomes, MT: mitochondria, GO: Golgi, PE: peroxisomes, CY: cytoplasm, ER: endoplasmic reticulum and NU: nucleus. For detailed information on individual spots/proteins, please refer to the additional files. 


\section{A}
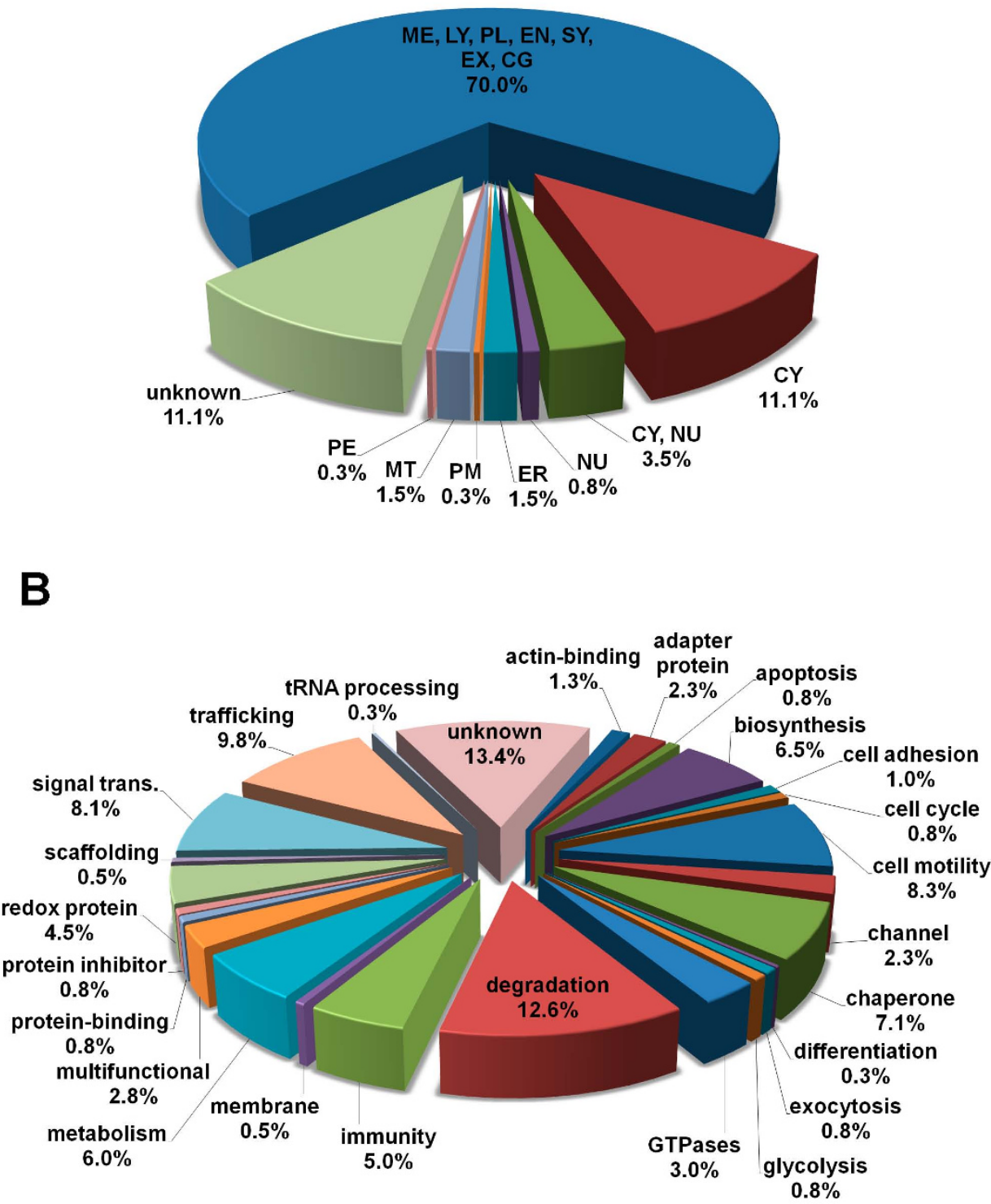

Figure 5 Classification of the identified proteins according to their localization (A) and function (B). The cellular localization and function of 397 identified proteins were classified as detailed in material and methods. Lysosomal and secretory vesicles are represented by melanosomes (ME), lysosomes (LY), platelet granules (PL), endosomes (EN), synaptosomes (SY), exosomes (EX) or cytolytic granules (CG). Other cellular compartments are: cytosol (CY), nuclei (NU), peroxisomes (PE), plasma membrane (PM), mitochondria (MT), golgi (GO) or endoplasmic reticulum (ER).

(ER, 1.5\%) and peroxisomal proteins (PE, 0.3\%) again underscores the selective enrichment of lysosomal organelles in the present study. In terms of function, the classification revealed a large heterogeneity and a broad spectrum of potential activities. However, as expected, proteins associated with degradation, signal transduction, trafficking and immunity formed about $35 \%$ of the total proteome of enriched SL (Figure 5B). The important role of these organelles in cytotoxicity is also supported by the identified effector molecules perforin (\#280) and granzyme A (\#707, 717, 720, 724).

Interestingly, and in contrast to the published SL proteome of NK cells [12], we did not detect significant amounts of granzyme $\mathrm{B}$ at the respective position in $2 \mathrm{D}$ gels from $\mathrm{T}$ cell blasts. However, this is in line with our previous observation that granzyme B might be stored in a separate compartment formed by electron dense granules that do not contain transmembrane FasL and 
that sediment as fraction 6 in our enrichment gradient [11]. To prove this result and address this issue in more detail, we started to analyze fraction 2 and fraction 6 vesicles (granzyme B granules). The direct comparison of the two granule populations by 2D DIGE and Western blotting clearly verified the result of the present analysis and provided first biochemical and proteomic evidence for two distinct species of cytotoxic effector vesicles in $\mathrm{T}$ cell blasts [18].

Surprisingly, it is still unknown to date whether functionally distinct TCR $\alpha \beta$ and TCR $\gamma \delta$ T cells, $\mathrm{CD}^{+}$and $\mathrm{CD}^{+} \mathrm{T}$ cells, $\mathrm{v} \delta 1^{+}$and $\mathrm{v} \delta 2^{+} \mathrm{T}$ cells, or normal and leukemic $\mathrm{T}$ cells also differ in terms of protein content and function of their lysosomal compartment(s). Based on the present description of the luminal proteome of FasL-containing secretory lysosomes in fully differentiated $\mathrm{T}$ cells, it will be possible to directly compare the content of cytotoxic effector organelles in different $\mathrm{T}$ cell subpopulations, e.g. by $2 \mathrm{D}$ difference gel electrophoresis. In addition, based on a larger set of marker proteins, the maturation of effector vesicles in the course of $\mathrm{T}$ cell activation can now be addressed in detail. Of note, using the applied protocol, we identified the luminal rather than the membrane proteome of this vesicular population. In addition, one has to consider that due to methodological limitations, the applied 2D technique might cover only about $20-30 \%$ of the total proteome and thus might be complemented in future studies employing LC-coupled mass spectrometric approaches.

\section{Conclusion}

We provide the first comprehensive proteome map of $\mathrm{T}$ cell-derived secretory lysosomes with only minor contaminations by cytosolic, nuclear or other proteins. This information will be useful to more precisely address the activation-dependent maturation and the specific distribution of effector organelles and proteins in individual $\mathrm{T}$ or NK cell populations in future studies.

\section{Methods \\ Cells}

Human peripheral blood mononuclear cells (PBMC) were isolated from buffy coat preparations by Ficoll density gradient centrifugation. For the generation of PHA-stimulated lymphoblasts, T cells were purified by magnetic cell sorting (MACS) using cell isolation kits from Miltenyi Biotech (Bergisch Gladbach, Germany). The cells were stimulated with phytohemagglutinin A (PHA, $0.5 \mu \mathrm{g} / \mathrm{ml}$, Remel, Lenexa, KS, USA) and expanded in the presence of irradiated EBV-transformed $B$ cells and allogenic PBMC and subsequently with recombinant interleukin 2 (rIL-2, $100 \mathrm{U} / \mathrm{ml}$, Chiron $\mathrm{GmbH}$, Marburg, Germany). Before the cells were analyzed on day 12-14, dead cells were removed by Ficoll-gradient centrifugation resulting in a $>98 \%$ pure $\mathrm{T}$ cell population as judged by CD3 FACS analysis.

\section{Confocal microscopy}

Cells were fixed with 3\% paraformaldehyde and permeabilized with $1 \%$ Triton X-100 as described [13]. The following antibodies were used: mouse IgG1 isotypecontrol MOPC-21 (Abcam, Cambridge, UK), anti-FasL mAb NOK1 (BD Biosciences, Heidelberg, Germany) with AlexaFluor488-conjugated goat anti-mouse IgG (Invitrogen, Karlsruhe, Germany), anti-CD63 mAb clone MEM-259 (Immunotools, Friesoythe, Germany) conjugated to AlexaFluor555 (Invitrogen), anti-Granzyme A-FITC (Immunotools) and anti-Cathepsin B (Santa Cruz Biotechnology, Santa Cruz, CA, USA) with AlexaFluor488-conjugated donkey anti-goat IgG (Invitrogen). Stained samples were mounted with ProLong Gold antifade reagent with DAPI (Invitrogen) and analyzed on a laser scanning microscope (LSM 510 Meta, Carl Zeiss, Jena, Germany) with appropriate filter settings. Images were acquired via scanning through the $x$-y-plane with $63 \times$ objective lense. Laser intensity and detectors were adjusted to a uniformly negative signal of the control samples stained with control IgG and second step antibodies.

\section{Subcellular fractionation}

For subcellular fractionation and enrichment of secretory lysosomes, at least $4 \times 10^{8} \mathrm{~T}$ cells were used. The fractionation procedure has been recently described in detail [11]. Briefly, the cells were mechanically disrupted and organelles were enriched by differential centrifugation steps. The enriched organelles were then loaded on a discontinuous density gradient (4.4 ml volume) with $27 \%, 22.5 \%, 19 \%, 16 \%, 12 \%, 8 \%$ Optiprep ${ }^{\circledR}$ which is a $60 \%$ Iodixanol solution (Sigma, Deisenhofen, Germany) and subjected to ultracentrifugation. Interphases were collected from the top of the gradient resulting in six $400 \mu$ fractions named and numbered 1 to 6 . The protein content in each fraction was determined using a Coomassie Protein Assay Reagent (Thermo, Rockford, IL, USA).

\section{Western blot analysis}

For Western blotting, $5 \mu \mathrm{g}$ of protein were separated by SDS-PAGE on pre-casted 4-12\% gradient Bis-Tris gels (Invitrogen). After transfer to nitrocellulose (NC) membranes (Biometra, Goettingen, Germany) and blocking with 5\% BSA or dry milk, the fractions were analyzed for subcellular marker proteins with the following antibodies: anti-FasL clone G-247.4 (BD Biosciences), anti-CD63 clone MEM-259 (Acris Antibodies, Herford, Germany), anti-LAMP-1 clone 25 (BD Biosciences), 
anti-cathepsin D clone CTD-19 (Sigma), anti-cytochrome oxidase IV (CoxIV) mAb clone 10G8D12C12 (1/1000, MitoScience, Eugene, OR, USA), anti pan-cadherin clone ab22744 (Abcam, Cambridge, UK) and horseradish peroxidase (HRP)-conjugated goat antimouse secondary antibody (GE Healthcare, Munich, Germany). Membranes were prepared for reprobing by incubation in stripping solution (100 mM 2-mercaptoethanol, $2 \% \mathrm{SDS}, 60 \mathrm{mM}$ Tris) for $25 \mathrm{~min}$ at $56^{\circ} \mathrm{C}$. ECL reagents in combination with Hyper Film (GE Healthcare) were used for chemiluminescence detection.

\section{Transmission electron microscopy}

Enriched organelles of fractions 2 and 5 were fixed with a mixture of $3 \%$ paraformaldehyde and $0.05 \%$ glutaraldehyde in $\mathrm{PBS}$ at $4^{\circ} \mathrm{C}$ overnight, washed in PBS, postfixed in $2 \% \mathrm{OsO}_{4}$, dehydrated in ethanol, and embedded in araldite (Sigma, Deisenhofen, Germany). Ultrathin sections were mounted on formvar-coated grids and double-stained with a saturated solution of uranyl acetate in $70 \%$ methanol and lead citrate. The grids were examined with a Zeiss EM 900 transmission electron microscope equipped with a digital camera system.

\section{D electrophoresis, image analysis and spot picking}

The 2D electrophoresis was performed as described before [11]. Briefly, SL pellets of fraction 2 were lysed on ice for $30 \mathrm{~min}$ with $30 \mu \mathrm{l}$ lysis buffer ( $\mathrm{pH}$ 8.5) containing $7 \mathrm{M}$ urea, $2 \mathrm{M}$ thiourea, $30 \mathrm{mM}$ Tris, $4 \%$ CHAPS. The supernatant was recovered after centrifugation for $20 \mathrm{~min}$ at $20.000 \times \mathrm{g}$ at $4^{\circ} \mathrm{C}$. A total amount of $250 \mu \mathrm{g}$ of protein was mixed with rehydration buffer (7 M urea, $2 \mathrm{M}$ thiourea, 4\% CHAPS, 2\% (v/v), IPG buffer $\mathrm{pH}$ 3-11 and 2\% (w/v) DTT) and applied by cuploading onto $24 \mathrm{~cm}$ non-linear pH 3-11 IPG gel strips for isoelectric focusing (IEF). The second dimension was performed on $26 \times 20 \mathrm{~cm}$ large $12.5 \%$ polyacrylamide gels after reduction and alkylation using the Ettan DALTsix large vertical electrophoresis system from GE Healthcare. The gels were removed from the glass plates, stained with Flamingo Pink (Bio Rad), mounted on a non-backed gel frame, scanned on a Typhoon Trio imager (GE Healthcare) and analyzed using Image Master 6.0 (GE Healthcare). Selected spots were picked with a $2 \mathrm{~mm}$ picking head. The picked gels were again scanned to verify the correct location of the punched spots.

\section{In-gel tryptic digestion and mass spectrometry}

Gel plugs were washed with water and $12.5 \mathrm{mM}$ ammonium bicarbonate $(\mathrm{ABC})$ in $50 \%$ acetonitrile $(\mathrm{ACN})$ and dehydrated in pure ACN. The dry gel pieces were rehydrated with $100 \mathrm{ng}$ sequencing-grade trypsin (Serva, Heidelberg, Germany) in $5 \mathrm{mM} \mathrm{ABC}$ and tryptic in-gel digestion was performed at $37^{\circ} \mathrm{C}$ overnight. For peptide extraction, $0.3 \%$ trifluoroacetic acid (TFA) in ACN was added and the samples were sonicated for $15 \mathrm{~min}$. The liquid phases were collected, lyophilized, redissolved in 0.5 to $1 \mu \mathrm{l}$ MALDI matrix solution $(3.2 \mathrm{mg} / \mathrm{ml} \alpha$-cyanohydroxycinnamic acid (Sigma) in 65\% ACN/0.1\% TFA), spotted onto 192-well stainless steel MALDI plates and air-dried. The samples were analyzed by peptide mass finger printing in positive reflectron mode followed by MSMS analyses of the most apparent five peptides using the 4700 Proteomics Analyzer mass spectrometer (Applied Biosystems, Framingham, MA, USA) as described elsewhere [12]. Peptide mass spectra were processed by internal calibration with autolytic fragments of porcine trypsin with $25 \mathrm{ppm}$ mass tolerance. MSMS spectra were acquired using default calibration updated prior to the run. Spectral data were searched against human proteins in the NCBI database (Homo sapiens, 192,176 entries) using MASCOT V2.0 (Matrix Sciences, London, UK).

\section{Database analysis}

Database searches with MASCOT were performed using the following parameters: the modification on cysteine residues by carbamidomethylation was set as obligate, methionine oxidation was considered as a potential modification; the maximum number of missed tryptic cleavages was one; the monoisotopic masses were considered and the mass tolerance was set to $\pm 50 \mathrm{ppm}$, and the fragment-ion mass tolerance was set to $0.2 \mathrm{Da}$ (MS/MS). A protein was accepted to be identified when the total protein score reached or exceeded the MASCOT score threshold ( $\geq 65$ with a probability of identification greater 95\%). A repeated search against a randomized decoy database (http://www.matrixscience. com/help/decoy_help.html) using the decoy.pl script and identical search parameters let to a false-positive rate of $1.2 \%$.

The classification according the localization and function of individual proteins was based on the Uni-Prot knowledge base, the iHOP database [19] and the iProXpress database [17] available through the Protein Information Resource (PIR) (GUMC, Washington DC, USA). Identified proteins were searched in this organelle-proteome reference dataset according to their Uni-Prot numbers.

\section{Additional material}

Additional file 1: Table S1. List of identified spots in enriched SL preparations from activated T cells. 742 spots representing 397 proteins were identified and annotated according to Figure S1 A-D. Proteins (3) are listed with spot numbers (1), the number of iterant identifications (2), respective NCBI accession (4) and Uni-Prot (5) numbers, theoretical molecular weights (MW) (6) and isoelectric points 
(pl) (7). In addition, the total MASCOT score (8), matched (9) and unmatched (10) peptides and the sequence coverage (11) are given. The protein function (12), and the subcellular localization (13) of the respective protein are assigned according to PIR, Uni-Prot and $\mathrm{iHOP}$ databases. Abbreviations: LY: Iysosomes, ME: melanosomes, PL: platelet granules, SL: secretory lysosomes, NG: neuromelanin granules, SY: synaptosomes, EX: exosomes, EN: endosomes, MT: mitochondria, GO: Golgi, PE: peroxisomes, CY: cytoplasm, ER: endoplasmic reticulum and NU: nucleus.

Additional file 2: Figure S1. Proteome map of enriched secretory lysosomes from T cells. The 742 annotated spots are displayed in fou separately enlarged quadrants (A-D) of one representative of the six performed 2D gels. Identifications are combined based on six repetitive experiments.

Additional file 3: Dataset S1. Protein identification data. Protein identification data are displayed as MASCOT's "Protein View" including matched peptides, sequence coverage and ion scores (for MS/MS identifications). Please use bookmarks for navigation.

\section{Acknowledgements}

This work was supported by grants from the German Research Foundation (SFB415 and 877), the Cluster of Excellence "Inflammation at Interfaces", the Innovationsfond Schleswig-Holstein, and the Medical Faculty of the Christian-Albrechts-University of Kiel.

\section{Author details}

${ }^{1}$ Institute of Immunology, Christian-Albrechts-University, UK S-H Campus Kiel, Kiel, Germany. ${ }^{2}$ Department of Zoophysiology, Zoological Institute, ChristianAlbrechts-University, Kiel, Germany. Institute of Anatomy, ChristianAlbrechts-University, Kiel, Germany.

\section{Authors' contributions}

HS and MN performed all experiments regarding cell culture, lysosome enrichment and 2D gel electrophoresis. MLet performed the confocal imaging experiments and was involved in the establishment of the lysosomal purification protocol. RL performed the electron microscopy. CG carried out all mass spectrometrical analyses. HS, MN and CG performed data analyses and assignments. HS, MLei, DK and OJ conceived of the study, and participated in its design and coordination. HS, CG and OJ drafted the manuscript. All authors read and approved the manuscript.

\section{Competing interests}

All authors declare that they have no competing interests.

Received: 1 December 2010 Accepted: 21 January 2011

Published: 21 January 2011

\section{References}

1. Blott EJ, Griffiths GM: Secretory lysosomes. Nat Rev Mol Cell Biol 2002, 3:122-131

2. Bright NA, Reaves BJ, Mullock BM, Luzio JP: Dense core lysosomes can fuse with late endosomes and are re-formed from the resultant hybrid organelles. J Cell Sci 1997, 110:2027-2040.

3. Carlsson SR, Fukuda M: Structure of human lysosomal membrane glycoprotein 1. Assignment of disulfide bonds and visualization of its domain arrangement. J Biol Chem 1989, 264:20526-20531.

4. Cuervo AM, Dice JF: A receptor for the selective uptake and degradation of proteins by lysosomes. Science 1996, 273:501-503.

5. Pols MS, Klumperman J: Trafficking and function of the tetraspanin CD63. Exp Cell Res 2009, 315:1584-92.

6. Fowler KT, Andrews NW, Huleatt JW: Expression and function of synaptotagmin VII in CTLs. J Immunol 2007, 178:1498-1504.

7. Lettau M, Schmidt $H$, Kabelitz D, Janssen O: Secretory lysosomes and their cargo in T and NK cells. Immunol Lett 2007, 108:10-19.

8. Bossi G, Griffiths GM: Degranulation plays an essential part in regulating cell surface expression of Fas ligand in T cells and natural killer cells. Nat Med 1999, 5:90-96
9. Blott EJ, Bossi G, Clark R, Zvelebil M, Griffiths GM: Fas ligand is targeted to secretory lysosomes via a proline-rich domain in its cytoplasmic tail. J Cell Sci 2001, 114:2405-2416.

10. Voss $M$, Lettau M, Paulsen $M$, Janssen O: Posttranslational regulation of Fas ligand function. Cell Commun Signal 2008, 6:11.

11. Schmidt H, Gelhaus C, Lucius R, Nebendahl M, Leippe M, Janssen O: Enrichment and analysis of secretory lysosomes from lymphocyte populations. BMC Immunol 2009, 10:41.

12. Schmidt H, Gelhaus C, Nebendahl M, Lettau M, Watzl C, Kabelitz D, Leippe M, Janssen O: 2-D DIGE analyses of enriched secretory lysosomes reveal heterogeneous profiles of functionally relevant proteins in leukemic and activated human NK cells. Proteomics 2008, 8:2911-2925.

13. Lettau M, Qian J, Linkermann A, Latreille M, Larose L, Kabelitz D, Janssen O: The adaptor protein Nck interacts with Fas ligand: Guiding the death factor to the cytotoxic immunological synapse. Proc Natl Acad Sci USA 2006, 103:5911-5916.

14. Lettau M, Pieper J, Janssen O: Nck proteins: Functional versatility in T cells. Cell Commun Signal 2009, 7:1.

15. Qian J, Chen W, Lettau M, Podda G, Zörnig M, Kabelitz D, Janssen O: Regulation of FasL expression: a SH3 domain containing protein family involved in the lysosomal association of FasL. Cell Signal 2006, 18:1327-1337.

16. Kassahn D, Nachbur U, Conus S, Micheau O, Schneider P, Simon HU, Brunner T: Distinct requirements for activation-induced cell surface expression of preformed Fas/CD95 ligand and cytolytic granule markers in T cells. Cell Death Differ 2009, 16:115-124.

17. Hu ZZ, Valencia JC, Huang $H$, Chi A, Shabanowitz J, Hearing VJ, Appella E, Wu C: Comparative Bioinformatics Analyses and Profiling of LysosomeRelated Organelle Proteomes. Int J Mass Spectrom 2007, 259:147-160.

18. Schmidt H, Gelhaus C, Nebendahl M, Lettau M, Lucius R, Leippe M, Kabelitz D, Janssen O: Effector granules in human T lymphocytes: Proteomic evidence for two distinct species of cytotoxic effector vesicles. J Proteome Res 2011, [Epub ahead of print].

19. Hoffmann $R$, Valencia $A: A$ gene network for navigating the literature. Nat Genet 2004, 36:664

doi:10.1186/1478-811X-9-4

Cite this article as: Schmidt et al:: Effector granules in human T lymphocytes: the luminal proteome of secretory lysosomes from human T cells. Cell Communication and Signaling 2011 9:4.

\section{Submit your next manuscript to BioMed Central and take full advantage of:}

- Convenient online submission

- Thorough peer review

- No space constraints or color figure charges

- Immediate publication on acceptance

- Inclusion in PubMed, CAS, Scopus and Google Scholar

- Research which is freely available for redistribution

Submit your manuscript at www.biomedcentral.com/submit
C Biomed Central 